\title{
Cefaléias e Neurotransmissão
}

\author{
Maurice B. Vincent, Ph.D. * \& Sérgio A.P. Novis **
}

\section{RESUMO}

As cefaléias sāo comuns e freqüentes, mas sua fisiopatologia ainda é desconhecida. A neurotransmissão anormal deve ser o mecanismo envolvido na produção das dores primárias. Vasos cranianos são inervados por fibras simpáticas, parassimpáticas e sensitivas. Os principais neurotransmissores envolvidos sāo a substância $P, 0$ peptideo relacionado ao gene da calcitonina, o peptideo intestinal vasoativo, o neuropeptídeo $Y$, a endotelina, entre outros. Muitas drogas usadas contra cefaléias atuam na transmissão neurovascular. O conhecimento dos mecanismos responsáveis pela gênese das cefaléias levará ao desenvolvimento de medicamentos mais eficazes.

\section{UNITERMOS}

Substância P. Peptideo relacionado ao gene de calcitonina. Peptideo intestinal vasoativo. Neuropeptídeo Y. Endotelina. Cefaléias. Sinalizaçāo celular. Sumatriptan.

- Chefe do Setor de Cefaléias, Serviço de Neurologia, Hospital Universitário Clementino Fraga Filho, Universidade Federal do Rio de Janeiro.

** Professor Titular de Neurologia, Universidade Federal do Rio de Janeiro.
Cefaléias são desordens comuns. A migrânea (enxaqueca) acomete milhões de pacientes em todo o mundo e é responsável por consideráveis prejuízos financeiros e sociais. Apesar dos avanços conseguidos, sobretudo ao longo da última década, a pesquisa de novas drogas anti-migranosas ainda é difícil, uma vez que a fisiopatologia das cefaléias primárias permanece desconhecida. Entretanto, aspectos recentemente observados no terreno da neurotransmissão, sobretudo em relação à junção nervo-vasocraniano, têm esclarecido alguns aspectos no fascinante campo das cefaléias primárias.

Durante décadas os médicos têm aceitado a noção de que a dor na cabeça está relacionada à dilatação arterial anormal. Por outro lado, a aura migranosa seria o resultado da vasoconstriç̧ão exagerada, levando a sintomas neurológicos focais. Este modelo simplificado vem sendo desafiado sobretudo após os anos $80^{5,26}$, embora não haja dúvidas de que os vasos devam participar de alguma forma na fisiopatologia das cefaléias, seja primária ou secundariamente. Nós apenas não sabemos ainda como.

\section{A INERVAÇÃO DOS VASOS}

No que se refere aos vasos cranianos, existem três classes e fibras nervosas: Fibras simpáticas, originadas no gânglio cervical superior; as fibras parassimpáticas, a partir do gânglio esfenopalatino, e as fibras sensitivas, a partir do gânglio de Gasser. Nós estamos todos bem habituados ao conceito de fibras aferentes (sensitivas) e eferentes (motoras). As fibras sensitivas trigeminais, porém, têm também função de fibra "eferente", liberando neurotransmissores antidromicamente na intimidade das paredes dos vasos, que podem desempenhar importantes ações vasoregularas.

Quais são os neurotransmissores envolvidos na inervação dos vasos cranianos ? Os neurotransmissores ditos "clássicos", como as catecolaminas, a acetilcolina (ACh) e o glutamato, têm sido reconhecidos há muitos anos. Todavia, uma inesgotável lista de neuropeptídeos vem sendo identificados como neurotransmissores e/ou neuromoduladores em diferentes áreas do sistema nervoso. Considerava-se que os neurônios podiam sintetizar e liberar apenas um neurotransmissor cada um - um conceito denominado "princípio de Dale" - até surgirem evidências a favor da co-existência de vários neurotrasmissores em uma única fibra nervosa ${ }^{3}$. A co-existência de peptídeos e neurotransmissores clássicos ou diferentes peptídeos está definitivamente aceita. Assim, fibras simpáticas liberam não apenas noradrenalina (NA), mas também Neuropeptídeo Y (NPY), um peptídeo vasoconstrictor de 36 aminoácidos. Fibras parassimpáticas possuem ACh, mas também o peptídeo 
intestinal vasoativo (VIP) e o peptídeo histidina isoleucina (PHI). As fibras sensitivas liberam peptídeos como a substância $\mathrm{P}$ (SP), o peptídeo relacionado ao gene da calcitonina (CGRP), a neuroquinina $A$ (NKA) e outras taquiquininas.

Analisadas em conjunto, as informações disponíveis hoje indicam que os vasos na cabeça têm uma inervação tripla. $O$ efeito final resultante da ativação de uma fibra nervosa depende da interação entre muitos nerotransmissores e fatores locais. Como exemplo, o endotélio produz vasodilatadores potentes, como o fator de relaxamento derivado do endotélio (EDRF, o qual parece ser o 6 xido nítrico, NO), bem como potentes vasoconstrictores, como é o caso das endotelinas (ET). O endotélio é também importante como um modulador local da atividade de outros neurotransmissores. Alguns vasodilatadores são endotélio-dependentes, uma vez que não induzem vasodilatação sem a presença de um endotélio funcionante. Este é o caso de SP e da $\mathrm{ACh}$. Por outro lado, o VIP e o CGRP induzem vasodilatação em algumas preparações livres de endotélio. Para compreender como os vasos participam da fisiopatologia das cefaléias, é necessário estudar detalhadamente a neurotransmissão nervovaso.

\section{SEROTONINA (5-HT) E CEFALÉIAS}

Outro aspecto interessante da neurotransmissão em relação às cefaléias é o papel da serotonina (5-HT). A 5-HT tem propriedades vasoativas e existe em fibras em torno de vasos da pia mater provenientes dos núcleos da rafe ${ }^{8}$. Em 1961, Sicuteri et al. encontraram um aumento do ácido 5-hidroxindolacético na urina durante ataques de migrânea ${ }^{1}$. Desde então, vários autores têm escrito a respeito das alterações envolvendo a 5-HT em migrâneas e cefaléias do tipo tensão. Um considerável número de medicamentos utilizados em cefaléias tem sua açāo de alguma forma relacionada à serotonina, como a metisergida e o pizotifeno (antagonistas $5 \mathrm{HT}_{2}$ ), os antidepressivos tricíclicos (inibidores da recaptação de 5-HT) e o sumatriptan, um interessante medicamento recentemente lançado e que atua como agonista dos sub-receptores serotoninérgicos $5-\mathrm{HT}_{1 \mathrm{~B} / \mathrm{D}^{31}}$. O Sumatriptan provou ser eficaz contra pelo menos migrânea $\mathrm{e}$ cefaléia em salvas. Interessantemente, ao lado de sua ação sabidamente vasoconstrictora, o sumatriptan pode bloquear a produção de inflamação neurogênica ao inibir em fibras sensitivas a liberação pré-juncional de neuropeptídeos vasoativos. Um dos autores deste artigo (MBV) descreveu um efeito vasodilatador do sumatriptan na artéria oftálmica suína isolada, o que pode indicar, mais uma vez, que o efeito terapêutico do sumatriptan pode não estar relacionado apenas às suas propriedades vasoconstrictoras ${ }^{38}$. O sumatriptan também reduziu o calibre da artéria cerebral média durante ataques de migrânea, aparentemente acompanhando a diminuição da dor ${ }^{23}$. Nós acreditamos que o mecanismo de ação do sumatriptan está mais relacionado à modulação da transmissão neuro-vascular (ou em outro território?) do que simplesmente às suas propriedades vasoconstrictoras. O sumatriptan, a droga de escolha para ataques de cefaléia em salvas e provavelmente também de migrânea, ${ }^{20,28}$ não é apenas um medicamento contra algumas cefaléias primárias, mas sobretudo uma importante ferramenta de pesquisa. Ele pode representar a primeira droga de uma nova classe de medicamentos antimigranosos com maior eficácia e menos efeitos colaterais.

\section{ALGUNS NEUROTRANSMISSORES SUPOSTAMENTE ENVOLVIDOS COM AS CEFALEIAS}

Quais são os efeitos dos neurotransmissores vasoativos? A SP, um peptídeo descoberto em 1931, têm atraído muita atenção como um neurotransmissor provavelmente envolvido com as cefaléias primárias. A chamada "teoria da SP" tornou-se popu$\operatorname{lar}^{10,21}$. Ela pode ser liberada por fibras não mielínicas do tipo $\mathrm{C}^{2}$ e induz relaxamento dependente do endotélio em vasos cranianos $^{7,22}$. Existem pelo menos três tipos de receptores para taquiquininas (a SP é uma taquiquinina), chamados NK1, NK2 e NK3. A SP é o agente mais potente dentro da família das taquiquininas. Ela induz miose em muitas espécies, juntamente com outros sinais inflamatórios oculares (ver ${ }^{35}$ para uma revisão). De fato, é tentador aceitar que a SP possa ser responsável pelas alterações oculares durante ataques de cefaléias em salvas. Todavia, a vasodilatação induzida pela SP é comparativamente breve e mais fraca ${ }^{33}$. Ela não induz lacrimejamento, uma vez que o aparelho lacrimal está sob controle parassimpático ${ }^{17}$. Embora seja um vasodilatador rápido (in vitro), ela é liberada a partir de fibras que estão localizadas na adventícia dos vasos ou entre a adventícia e a média, ao passo que sua ação vasodilatadora depende da participação do endotélio. Assim, é difícil entender como a SP originada em fibras nervosas possa atuar como um vasoregulador rápido, uma vez que precisa atingir primeiramente o endotélio, que por sua vez libera NO, o qual produz vasodilatação por agir na camada média do vaso. É mais provável que a SP circulante ou produzida pelo próprio endotélio atue como vasomodulador, uma vez que estaria localizada mais próxima ao seu ponto de atuação.

o CGRP, um peptídeo de 37 aminoácidos codificado no mesmo gene da calcitonina, ${ }^{9,35}$ co-existe com a SP em fibras sensitivas e induz vasodilatação ${ }^{11,14}$. Seus efeitos são comparativamente mais lentos, prolongados e mais intensos ${ }^{29,33}$. O CGRP se liga a receptores CGRP-1, sensíveis ao antagonista do CGRP, o $\alpha$-CGRP, 8-37; ou ao receptor CGRP-2, insensível ao referido antagonista. Se um neuroptídeo sensitivo estiver envolvido com a produção de cefaléias, nós acreditamos que o CGRP é o melhor candidato identificado até hoje. Pelo menos em felinos, existem mais neurônios contendo CGRP no gânglio de Gasser do que células contendo $\mathrm{SP}^{12}$. Tem sido demonstrado que o CGRP está aumentando no sangue coletado da jugular externa ipsilateral a ataques de migrânea ${ }^{19,36}$. De maneira interessante, existem evidências sugerindo que o sumatriptan reduz 
a dilatação arterial ao mesmo tempo que normaliza a dor ${ }^{23}$ Claramente, novas pesquisas acerca dos neuropeptídeos sensitivos vão esclarecer aspectos ainda obscuros na fisiopatologia das cefaléias.

O importante substrato anatômico para a produção de cefaléias composto pelas fibras sensitivas trigeminais e os vasos cranianos têm sido conhecido como o "sistema trigeminovascular". A assim chamada "inflamação neurogênica", um fenômeno que envolve extravasamento de plasma induzido por ativação antidrômica de fibras sensitivas, têm sido estudada detalhadamente pelo grupo de Moskowitz ${ }^{15}$. Basicamente, ele propõe que fatores desencadeantes ainda desconhecidos ativam fibras trigeminais perivasculares que conduzem impulsos ortodrômica e antidromicamente. Isto leva à liberação periférica de SP, CGRP e substâncias afins, induzindo inflamação neurogênica. Por outro lado, a condução ortodrômica conduz informação nociceptiva para o tronco cerebral e níveis mais altos no sistema nervoso central. O sumatriptan e a diidroergotamina (DHE) bloqueiam pré-juncionalmente a inflamação neurogênica e inibem a liberação de CGRP (e provavelmente outros neurotransmissores) a partir das fibras trigeminais ${ }^{37}$.

Muitos autores consideram que a depressão alastrante (DA), um fenômeno cortical descrito pelo neurofisiologista brasileiro Leão, está de alguma maneira relacionada às cefaléias, particularmente migrânea com aura. Estudos recentes indicam que a SD pode ativar áreas do tronco cerebral onde a informação nociceptiva trigeminal é processada ${ }^{13}$. A real relação entre a DA, peptídeos vasoativos, e inflamaçāo neurogênica ainda é desconhecida, e têm sido objeto do nosso estudo no momento.

O VIP, um peptídeo de 28 aminoácidos com propriedades vasodilatadoras isoladas primeiramente no duodeno de porcos, co-existe com ACh em algumas fibras parassimpáticas. Ele induz dilataçāo em vasos cranianos, um efeito aparentemente independente de células endoteliais ${ }^{6}$. Parece haver dois receptores para VIP, com baixa e alta afinidade, respectivamente. $\mathrm{O}$ VIP é importante para a regulação do lacrimejamento, e pode ser que seja anormalmente liberado durante ataques que cefaléia em salvas. (veja ${ }^{35}$ para uma revisão). Um de nós (MBV) encontrou que o relaxamento induzido por VIP em artérias oftálmicas suínas isoladas foi reduzido pelo sumatriptan ${ }^{38}$. A ACh também dilata vasos cerebrais, um efeito dependente do endotélio ${ }^{4}$.

O NPY e o NA co-existem em fibras nervosas simpáticas. Ambos têm propriedades vasoconstrictoras, mas os efeitos do NPY podem variar de acordo com o vaso estudado. Em alguns tecidos ele modula a contração induzida por noradrenalina (NA), mas em outros esta interação não está presente. O real papel dos neurotransmissores parassimpáticos ainda é pouco conhecido. A miose ipsilateral que ocorre em pacientes com cefaléia em salvas não representa uma real síndrome de Claude Bernard Horner, uma vez que estes pacientes apresentam aumento da sudorese na região frontal ipsilateral, o que não está de acordo com as lesões simpáticas.

As endotelinas (ET) pertencem a uma família recém-descrita de potentes peptídeos vasoconstrictores ${ }^{16,18}$. Existem pelo menos três tipos de endotelinas, denominadas ET-1, ET-2,
ET-3; e pelo menos dois receptores, chamados ETA (ET-1 seletivo); ETB (ET-1-não-seletivo) e, talvez, ETC ${ }^{27,32}$. Curiosamente, as ETs podem induzir também dilatações, dependendo da preparação e da concentração utilizada. A resposta constrictora está provavelmente relacionada ao receptor $\mathrm{ET}_{\mathrm{A}}$ no músculo liso vascular, ao passo que a dilatação parece estar relacionada a receptores $\mathrm{ET}_{\mathrm{B}}{ }^{25}$. A ET-1 é a forma mais importante encontrada em suínos e humanos, e pode estar implicada na fisiopatologia das cefaléias. Existem evidências sugerindo que a ET seja também um neurotransmissor, tendo sido encontrada em gânglios sensitivos e simpáticos (ver ${ }^{24}$ ). As interações entre ET e peptídeos vasodilatadores, com potencial implicações em cefaléias, têm sido estudadas em artérias oftálmicas suínas isoladas. A ET diminui o relaxamento induzido por CGRP este diminui a contração induzida por ET. O padrão das reações da ET e do CGRP ao longo do tempo são similares ${ }^{29}$. Considerando-se as respostas constrictoras à ET, o CGRP é provavelmente o agente natural "anti-ET". Isto pode ter importância para a regulação do tono vascular durante ataques de migrânea e/ou cefaléia em salvas. No futuro, é possível que um agente com prioridades agonistas para ET venha a ter utilidade terapêutica.

\section{SISTEMAS DE SINALIZAÇÃO CELULAR E "SEGUNDO-MENSAGEIROS"}

O que acontece em uma célula quando um receptor é acionado pelo transmissor apropriado? $\mathrm{O}$ acoplamento leva a uma série de reaçōes que se iniciam na membrana celular e ativa enzimas citoplasmáticas e íons que produzem efeitos específicos. As substâncias produzidas após o acoplamento do transmissor com seu receptor são denominadas "segundo-mensageiros" (second messengers). Os segundos-mensageiros são proteína-quinases dentro da célula. Existem pelo menos três sistemas de sinalização celular conhecidos, mas este quebra-cabeças complexo parece não ter fim e está longe de ser compreendido. Os sinais que as células trocam entre si ainda são um mistério. Para uma boa revisão sobre sistemas de sinalização celular, ver TIBS, vol. 17, 1992. A figura I mostra o esquema geral dos sistemas de sinalização celular.

O primeiro sistema é o do AMP cíclico (cAMP). Isto é o que se ativa por exemplo pela NA. Quando um receptor $\beta$-adrenérgico - um receptor acoplado a proteínas especiais chamadas proteínas $\mathrm{G}$ - é ativado pela NA, ativa-se a adenilatociclase, o que leva à produção de cAMP. Este segundo-mensageiro ativa uma proteína-quinase cAMP-dependente, que por sua vez irá fosforilar muitas proteínas intracelulares.

O segundo sistema é o do inositol-trisfosfato/diacilglicerol (IP3-DAG). Este é o caso do que ocorre quando da ativação de um receptor muscarínico (acoplado a proteínas $\mathrm{G}$ ) pela $\mathrm{ACh}$. Isto faz a fosfolipase $\mathrm{C}$ (PLC) produzir IP3 e DAG a partir do fosfatidilinositol 4,5-bisfosfato (Ptdlns(4,5) $\mathrm{P}_{2}$ ). O IP 3 mobiliza $\mathrm{Ca}^{2+}$ de estoques intracelulares e o DAG ativa a proténa-qui- 


\section{Figura 1}

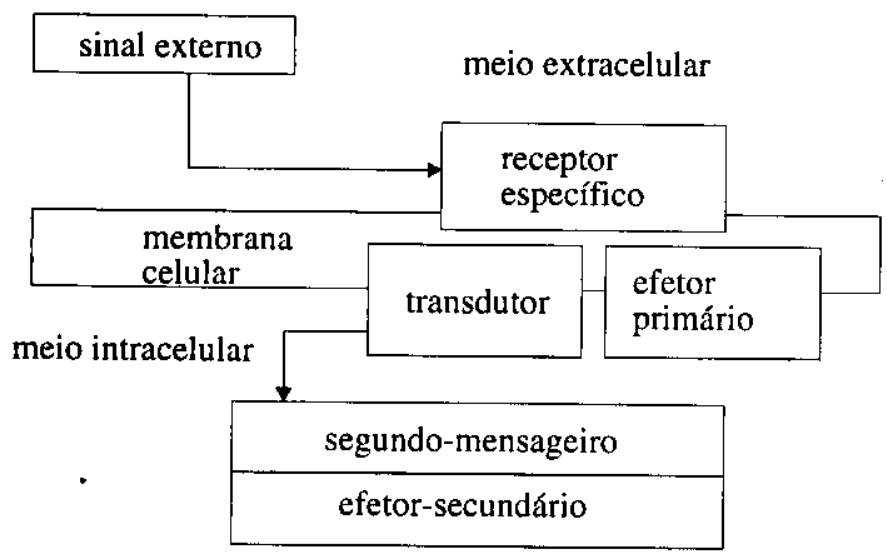

Legenda: Os sistemas de sinalização celular obdecem ao modelo exemplificado nesta figura. Após o estímulo de receptor, uma molécula transdutora ativa um receptor primário que por sua vez estimula os segundo-mensageiros, levando aos efeitos secundários.

nase $\mathrm{C}(\mathrm{PKC})$, que por sua vez controla respostas na célula como por exemplo secreção e liberação de diversas substâncias. A ativação da fosfolipase $A 2$ provoca ativação sustentada da PKC, determinando respostas tardias e.g. proliferaçāo e diferenciaçāo.

O terceiro sistema é o do ácido aracdônico (AA). Quando, por exemplo, a histamina se liga ao seu receptor, o AA é liberado a partir de fosfolipídeos de membrana após ativação da fosfolipase A2. O AA é o precursor dos eicosanóides, pela ação da ciclooxigenase e da lopooxygenase. A prostaglandina e os tromboxanos podem também mediar reações vasculares.

Todos os neurotransmissores citados acima ativam um ou outro sistema de sinalização celular. O CGRP e o VIP podem ativar o cAMP, e a ET-1 ativa o sistema IP3-DAG, por exemplo. Medicamentos usados na terapia das cefaléias podem atuar em sistemas de sinalização celular. O lítio, uma das opções terapêuticas no caso da cefaléia em salvas, pode bloquear uma série de passos no ciclo metabólico do inositol ${ }^{13}$. Esta pode ser a razão pela qual o lítio modifica o efeito da ET-1 na artéria temporal humana isolada ${ }^{30}$. Os inibidores da ciclooxygenase modificam a vasoatividade induzida por peptídeos vasoativos em artérias oftálmicas suínas isoladas ${ }^{34}$.

\section{CONSIDERAÇÕES FINAIS}

Os verdadeiros mecanismos responsáveis pelas cefaléias "primárias" são desconhecidos. Nós estamos convencidos de que estas condições se devem a desordens na neurotransmissão. Para entender a dor, deve-se estudar como a neurotransmissão ocorre no sistema nervoso, nos vasos e nos olhos. Isto inclui também os sistemas de sinalização celular envolvidos. Tal estudo pode levar ao desenvolvimento de novos agentes terapêuticos com menos efeito colaterais e maior eficácia.

\section{SUMMARY}

Headaches are common and frequent disorders, but the pathophysiology of primary head pain remains obscure. impaired neurotransmission might be the source of paroxysmal head pain. Vessels in the head are innervated by sensory, parasympathetic and sympathetic fibres. The main transmitters involved are substance $P$, calcitonin gene-related peptide, vasoactive intestinal peptide, neuropeptide $Y$ and endothelin, among others. Several drugs used against headaches act in neurovascular transmission. The understanding of the mechanisms behind head pain will lead to new effective therapeutic agents.

\section{KEY WORDS}

Substance $P$. Calcitonin gene-related peptide. Vasoactive intestinal peptide. Neuropeptide Y. Endothelin. Headaches. Cellular signalling. Sumatriptan.

\section{Bibliografia}

1 SICUTERI, F., TESTI, A., ANSELMI, B. - Biochemical investigations in headache: increase in hydroxyindoleacetic acid excretion during migraine attacks. Int Arch Allergy 19,55-58, 1961.

2 HÖKFELT, T., KELLERTH, J-O., NILSSON, G., PERNOW, B. Experimental immunochemical studies on the localization and distribution of substance $P$ in cat primary sensory neurons. Brain Res 100, 235-252, 1975.

3 BURNSTOCK, G. - Do some nerve cells release more than one transmitter? Neuroscience 1, 239-248, 1976.

4 FURCHGOTT, R.F., ZAWADZKI, J.V. - The obligatory role of endothelial cells in the relaxation of arterial smooth muscle by acetylcholine. Nature 288, 373-376, 1980.

5 OLESEN, J., LARSEN, B., LAURITZEN, M. - Focal Hyperemia followed by spreading oligemia and impaired activation of $\mathrm{rCBF}$ in classic migraine. Ann Neurol 9, 344-352, 1981.

6 DUCKELS, S. P., SAID, S.1. - Vasoactive intestinal peptide as a neurotransmitter in the cerebral circulation. Eur J Pharmacol 78, 371-374, 1982.

7 EDVINSSON, L., UDDMAN, R. - Immunohistochemical localization and dilatory effect of substance $P$ on human cerebral vessels. Brain Res 232, 263-273, 1982.

8 EDVINSSON, L., DEQUEURCE, A., DUVERGER, D., MACKENZIE, E.T., SCATTON, B. - Central serotonergic nerves project to the pial vessels of the brain. Nature 306, 55-57, 1983.

9 ROSENFELD, M.G., MERMOD, J.J., AMARA, S.G., SWANSON, L.W., SAWCHENKO, P.E., RIVIER, J., VALE, W. W., EVANS, R.M. - Production of a novel neuropeptide encoded by the calcitonin gene via tissue specific RNA processing. Nature 304, 129-135, 1983.

10 HAROEBO, J. E. - The involvement of trigeminal substance $P$ neurons in cluster headache. An hypothesis. Headache 24, 294-304, 1984.

11 BRAIN, S.D., WILLIAMS, T.J., TIPPINS, J.R., MORRIS, H.R., MACINTYRE, I. - Calcitonin gene-related peptide is a potent vasodilator. Nature 313, 54-56, 1985.

12 UDDMAN, R., EDVINSSON, L., EKMAN, R., MCCULLOCH, J., KINGMAN, T.A. - Innervation of the feline cerebral vasculature by 
nerve fibres containing calcitonin gene-related peptide: trigeminal origin and co-existtance with substance P. Neurosci Lett 62, 131$136,1985$.

13 NAHORSKI, S.R., JENKINSON, S., CHALLISS, R.A.J. - Lithium-induced disruption of cell signalling in brain: evidence implicating the phosphoinositide cycle. Acta Pharmacol Toxicol [suppl 1], 42-48, 1986

14 UDDMAN, R., EDVINSSON, L., EKBLAD, E., HAKANSON, R., SUNDLER, F. - Calcitonin gene-related peptide (CGRP): perivascular distribution and vasodilatory effects. Regul Pept 15, 1-24, 1986.

15 MARKOWITZ, S., SAITO, K., MOSKOWITZ, M.A. - Neurogenically mediated leakage of plasma protein occurs from blood vessels in dura mater but not brain. J Neurosci 7, 4129-4136, 1987.

16 YANAGISAWA, M., KURIHARA, H., KIMURA, S., TOMOBE, Y., KOBAYASKY. M., MITSUI, Y., GOTO, K., MASAKI, T.- A novel potent vasoconstrictor peptide produced by vascular endothelia cells. Nature 332, 411-415, 1988.

17 DARTT, D.A. - Signal tranduction and control of lacrimal protein secretion: a review. Curr Eye Res 8, 619-636, 1989.

18 INOUE, A. YANAGISAWA, M., KIMURA, S., KASUYA, Y., MIYAUCHI, T., GOTO, K., MASAKI, T. - The human endothelin family: three structurally and pharmacologically distinct isopeptides predicted by three separate genes. Proc Natl Acad Sci 86, 2863-2867, 1989.

19 GOADSBY, P.J., EDVINSSON, L., EKMAN, R. - Vasoactive peptide release in the circulation of humans during migraine headaches. Ann Neurol 28, 183-187, 1990

20 PEROUKTA, S.J. - Sumatriptan in acute migraine: pharmacology and review of world experience. Headache 30[suppl 2], 554-560, 1990.

21 SICUTERI, F. FANCIULLACI, M., NICOLODI, M., GEPPETTI, P., FUSCO, B.M., MARABINI, S., ALLESTRANDRI, M., CAMPAGNOLO, V. - Substance $P$ theory: a unique focus on the painful and painless phenomena of cluster headache. Headache $30,69-79$, 1990.

22 EDVINSSON, L. - Innervation and effects of dilatory neuropeptides on cerebral vessels. New aspects. Blood Vessels 28, 35-45, 1991.

23 FRIBERG, L., OLESEN, J., IVERSEN, H.K., SPERLING, B. - Migraine Pain associated with middle cerebral artery dilatation: reversal by sumatriptan. Lancet 338, 13-17, 1991.

24. HEMSÉN, A. - Biochemical and functional characterization of endothelin peptides with special reference to vascular effects. Acta Physiol Scand 142[suppl 602], 1991.

25 IHARA, M., NOGUCHI, K., SAEKI, T.; TSUCHIDA, S., FUKAMI, T., ISHIKAWA. K., NISHIKIBE, M., YANO, M. - Biological profiles of highly potent novel endothelin antagonists selective for the ETA receptor. Life Sci 50, 247-255, 1991.

26 OLESEN, J. - Cerebral and extracranial circulatory disturbances in migraine: pathophysiological implications. Cerebrovasc Brain Metab Rev 3, 1-28, 1991.
27 SHINI, V.B., VANHOUTTE, P.M. - Endothelin-1: a potent vasoactive peptide. Pharmacol Toxicol 69, 303-309, 1991.

28 THE SUMATRIPTAN CLUSTER HEADACHE STUDY GROUP., Treatment of acute headache with sumatriptan. N Eng J Med 325, 322-326, 1991.

29 BAKKEN, I.B., VICENT, M.B., WHITE, L.R., JUUL, R., EDVINSSON, L., SJAASTAD, O. - Mutual modification of vasoactivity by calcitonin gene-related peptide and endothelin-1 in isolated porcine ophthalmic artery. Neuropeptides 23, 209-214, 1992.

30 BAKKEN, I.J., VINCENT, M.B., WHITE, L.R., CAPPELEN, J., SKAANES, K. O., SJAASTAD, O. - LOW concentrations of lithium and cyclooxygenase inhibitors enhance endothelin-1 (ET-1)-induced contractions in human temporal artery, but not in porcine ophthalmic artery. Headache 32, 475-479, 1992.

31 LANCE, J.W. - History of involvement of 5-HT in primary headaches. in: OLESEN, J. \& SAXENA, P.R. 5-hydroxytryptamine mechanisms in primary headaches. New York, Raven Press, 1992, pp. 19-28.

32 SAKURAI, T., YANAGISAWA, M., MASAKI, T. - Molecular characterization of endothelin receptors. Trends Pharmacol Sci 13, 103108, 1992.

33 VINCENT, M.B., WHITE, L.R., ELSAS, T., QVIGSTAD, G., SJAAS$T A D, O$. -Substance $P$ augments the rate of vasodilation induced by calcitonin gene-related peptide in porcine opthalmic artery in vitro. Neuropeptides 22, 137-141, 1992.

34 VINCENT, M.B. - Cyclooxygenase inhibitors modify the relaxant effect of vasoactive intestinal polypeptide and substance $P$ in isolated porcine ophthalmic artery. Cephalalgia 12, 15-19, 1992.

35 VINCENT, M.B. - Vasoactive peptides in the ocular/forehead area. Association with headache. Thesis. Trondheim, Tapir, 1992.

36 GOADSBY, P.J., EDVINSSON, L. - The trigeminovascular system and migraine: studies characterizing cerebrovascular and neuropeptide changes seen un humans and cats. Ann Neurol 33, 48-56, 1993.

37 MOSKOWITZ, M.A., NOZAKI, K., KRAIG, R.P. - Neocortical spreading depression provokes the expression of $c$-for protein-like immunoreactivity within trigeminal nucleus caudalis via trigeminovascular mechanisms. J Neurosci 13, 1167-1177, 1993.

38 VINCENT, M.B. WHITE, L.R., BAKKEN, I.J., SJAASTAD, O. - Sumatriptan relaxes isolated porcine ophthalmic artery, but inhibits VIP-jnduced relaxation. Cephalalgia 13, 378-382, 1993.

Correspondência para $M B V$

Av. das Américas, $1155 / 504$

22613.000 Rio de Janeiro, Brazil

Telefax: (021) 290.7155

e-mail: vicent $@$ brincc.bitnet 